\title{
Improved Appliance Coordination Scheme with Waiting Time in Smart Grids
}

\author{
Firas A. Al Balas, Wail Mardini, Yaser Khamayseh, Dua'a Ah.K.Bani-Salameh \\ Department of Computer Science,Jordan University of Science and Technology, Jordan \\ Irbid, Jordan 22110
}

\begin{abstract}
Smart grids aim to merge the advances in communications and information technologies with traditional power grids. In smart grids, users can generate energy and sell it to the local utility supplier. The users can reduce energy consumption by shifting appliances' start time to off-peak hours. Many researchers have proposed techniques to reduce the previous issue for home appliances, such as the Appliances Coordination (ACORD) scheme and Appliances Coordination with Feed In (ACORD-FI) scheme.

The goal of this work is to introduce an efficient scheme to reduce the total cost of energy bills by utilizing the ACORD-FI scheme to obtain an effective solution. In this work three scheduling schemes are proposed: the Appliances Coordination by Giving Waiting Time (ACORD-WT), the Appliances Coordination by Giving Priority (ACORD-P), and using photovoltaic (PV) with priority and waiting time scheduling algorithms.

A simulator written in $\mathrm{C}++$ is used to test the performance of the proposed schemes using. The performance metric used is the total savings in the cost of the energy bill in dollars. The first comparison for the proposed schemes with the ACORD-FI, and the results show that the efficiency of the proposed ACORD-WT is better than the ACORD-FI, regardless of the number of appliances. Moreover, the proposed ACORD-P, is also better than the standard ACORD-FI.
\end{abstract}

\section{Keyword—smart grids; energy bill; off-peak}

\section{INTRODUCTION}

Energy sources are classified into renewable and nonrenewable sources. Renewable sources are those that can be accessible to humans in a timely scaled manner that comes from natural resources on a regular or irregular basis. For example, sunlight is available on a daily basis in the summertime in many areas around the world. However, the wind would be available in some areas on a regular basis and would be slightly useful in others around the world. A renewable source contains many sources that can be listed as follows: tidal power, wave power, solar power, wind power, hydroelectricity, radiant energy, geothermal power, biomass, compressed natural gas, and nuclear power.

On the other side, nonrenewable sources are those that do not renew in enough amounts. For example, coal needs thousands of years to build naturally and cannot be available at a relevant rate of consumption. Examples of such sources are petroleum, coal, natural gas, and nuclear power.

Electricity is an energy form called electricity energy, and it is not similar to the other sources of energy, such as coal, petroleum, and solar energy. It is defined as the set of physical phenomena associated with the flow of an electric charge. The traditional sources of generating electricity were nonrenewable sources but can be generated from renewable sources [1].

Electrical devices that are common in homes are ovens, washers, dishwashers, televisions, microwaves, and others. Each one can consume an already measured amount of energy, and with the demand for electricity increasing, energy consumption has increased. Therefore, the cost of energy consumption also has increased.

The increasing demand for electricity in the future must proceed through updating the electric grid and creating smart ones. The term "grid" refers to the electrical distribution system, which transmits electricity from power plants located near fuel sources to the consumption locations, where the previous electric grid or the traditional grid has worked well for many years. Fig. 1 shows the traditional power infrastructure.

The smart grid was founded to solve the increasing demands on electricity. The smart grid establishes and distributes electricity more efficiently, economically, and securely, and it combines different technologies, products, services, from generation, transmission, and distribution to and from consumer appliances by using advanced sensing, communications, and control technologies [2]. Fig. 2 shows the modern power infrastructure (smart grid).

Smart-grid technologies can control and monitor the power consumption in both homes and buildings, where each device has different operations that can be used and scheduled, resumed, suspended, and stopped by a smart meter. The smart meter enables scheduling of these operations, which ensures savings by 1) reducing the energy during peak demand time, 2) reducing cost, 3) increasing reliability, 4) and reducing power-interruption periods.

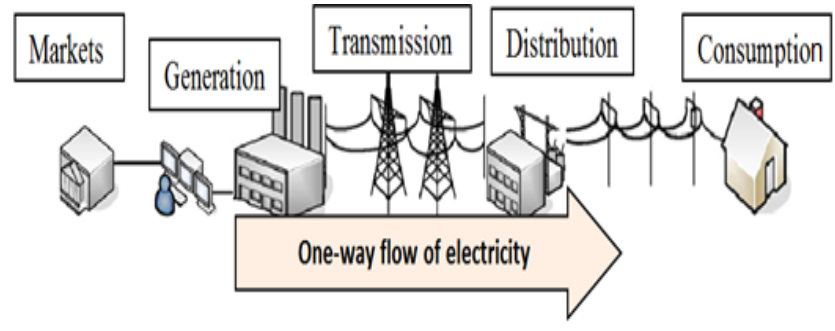

Fig. 1. Traditional power infrastructure 


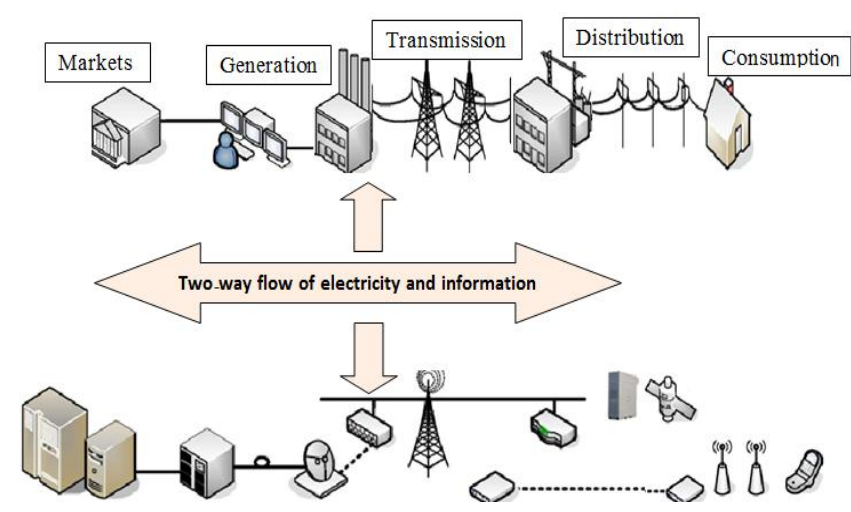

Fig. 2. Modern power infrastructure (smart grid)

The smart grid consists of four main parts [3]:

1) Advanced Transmission Operations (ATS) aim to achieve intelligent transmission and decrease the risk of failure.

2) Advanced Metering Infrastructure (AMI) is considered a key component of the smart grid because it deploys communication networks to connect each customer with utility companies and also interacts with smart meters for scheduling the energy management.

3) Advanced Distribution Operations (ADO) are full automation of all control devices, and their primary focus is on the self-healing capabilities of the smart grid.

4) Advanced Asset Management (AAM) deals with the management of the industrial equipment at the user.

Smart grids have many objectives; they allow for a twoway flow of information between consumers and utility, improve energy storage, are self-healing, environmentally friendly and able to implement consumer energy management policies [18]. However, smart grids face many challenges such as regulation, standardization, and security.

The drivers that are involved in developing the smart grids can is into three groups: the government, customer behavior, and industry and technology changes. Fig. 3 shows the smartgrid layout.

\section{A. Wireless Sensor Networks (WSNs)}

Wireless sensor networks (WSNs) are an essential part of smart grids and provide low-cost, low-power solutions. Some applications of WSNs in smart grids are the home appliance and environment monitoring that include consumption and fault detection. The main challenges faced by WSNs' applications in smart grids are hard environmental conditions (e.g., high humidity levels, vibrations, dirt, and dust), security issues, resource constraints, packet errors, and system reliability. There are three resources (energy, memory, and processing) responsible for the design and implementation of WSNs [6].

\section{B. Electrical devices}

Electrical devices can consume major amounts of energy (for example, washers, dishwashers, dryers, coffee makers, plug-in hybrid electric vehicle (PHEV), and air conditioners). Each device consumes a specific amount of electrical energy that can be measured in $\mathrm{kWh}$ and can be scheduled to reduce energy cost and consumption.

Each device has many different cycles with different energy-consumption level for each. The duration time in minutes for each cycle are 10,30,60,60,60, and 90 for a coffee maker, washer, dryer, PHEV, air conditioner, and dishwasher, respectively, where the energy consumption for each device is $0.4,0.89,2.46,9.9,1.5$, and 1.19 , respectively [4].

PHEV cars are hybrid electric vehicles equipped with researchable batteries in addition to the traditional liquid fuel tank. The battery fully charged by linking the plug with an external electric power source. Most PHEVs are recharged during off-peak hours. The cost of electricity to operate the hybrid car has been estimated at less than one quarter the cost of gasoline. Also, they reduce air pollution. Typical recharging of a PHEV battery takes several hours. The quickmode charge to around $80 \%$ capacity may take as little as 30 minutes. Most PHEVs need $0.2-0.3 \mathrm{kWh}$ charging power for 1 mile of driving. The energy consumption for this device is $9.9 \mathrm{kWh}[5]$.

A washing machine is a typical appliance that exists in almost every home. Electrical energy is used for driving the drum motor and heating up the water. The energy consumption for this device is typically around $0.89 \mathrm{kWh}$.

A dryer uses huge amount of energy to remove the humidity from the clothes. It was invented in England and France in the early 1800s. It is used commonly nowadays in North America. The energy consumption for this device is around $2.46 \mathrm{kWh}$.

A dishwasher is a mechanical device that is used in cleaning dishes and may be found in many restaurants and homes. The amount of energy used depends on whether it is connected to hot or cold water. The power consumption for this device is $1.19 \mathrm{kWh}$.

An air conditioner (AC) is used in many places to control the temperature of the limited area around it. Its cooling capacity is measured regarding BTU and considered as the amount of power used to lower the temperature of the air. There are different types of AC systems: window, split unit, and central AC. The capacity of the window and split-unit type is around 6000-24000 BTU, while the capacity of the central type is around 9000-60000 BTU. The energy consumption for this device is typically $1.5 \mathrm{kWh}$ [6]. A coffee maker is used commonly to make coffee in western countries, and there are many different types. The power consumption for this device is $0.4 \mathrm{kWh}$.

TABLE I. ENERGY CONSUMPTION AND CYCle DURATION OF APPLIANCES

\begin{tabular}{|l|l|l|}
\hline Appliance & $\begin{array}{l}\text { Energy consumption } \\
(\mathbf{k W h})\end{array}$ & Duration (min) \\
\hline Washer & 0.89 & 30 \\
\hline Dishwasher & 1.19 & 90 \\
\hline Dryer & 2.46 & 60 \\
\hline Coffee Maker & 0.4 & 10 \\
\hline PHEV & 9.9 & 60 \\
\hline AC & 1.5 & 60 \\
\hline
\end{tabular}




\section{Real Time Pricing}

There are different pricing schemes proposed in typical power grids; some are specific for smart grids, for example, Real Time Pricing (RTP), Time of Use (TOU), Critical Peak Pricing (CPP), Day Ahead Pricing (DAP), and Inclining Block Rate (IBR).

The previous schemes are used widely. For example, the TOU pricing scheme is used in the Appliances Coordination with Feed In (ACORD-FI), Optimization-Based Residential Energy Management (OREM), and in-Home Energy Management (iHEM). Also, RTP is used in the Residential Energy Load Consumption (RLC) scheme, where TOU and CPP pricing are used in a decision support tool scheme [13].

In RTP, the price is changed hourly and is fixed during the period. RTP reflects the wholesale prices, weather conditions and generator failures.

\section{Job Scheduling}

Job scheduling is the process of deciding how to assign resources to different tasks to optimize one or more objectives, such as minimum waiting time and maximum response time. The job is scheduled by using priorities, delay, and custom scheduling conditions [7].

Scheduling algorithms are required for most modern systems to perform the multitasking (e.g., operate more than one process at the same time) and multiplexing (send multiple flows at one time). The scheduling can be classified as preemptive or non-preemptive scheduling. Following is a detailed description of those scheduling types.

In this paper, we used the preemptive scheduling used in real-time systems. It implements the highest priority task of all those tasks that are currently ready to implement.

Preemptive scheduling includes Priority and Round Robin (RR) algorithms. In Priority Preemptive scheduling, each process at the ready list is in descending order by its priority, so the process in the beginning of the list has the highest priority and is picked first by the scheduling algorithm. However, in RR scheduling, each process has a small unit of time, and the jobs move to the next process and continue until all processes are completed.

Non-preemptive scheduling is defined as when a process enters the state of operation; the state of that process is not removed from the scheduler until it is completed. Nonpreemptive scheduling includes the algorithms of First Come First Served (FCFS) and Shortest Job First (SJF). FCFS, which is also known as First in First Out (FIFO), is the simplest scheduling algorithm. The jobs are completed in the same order they arrive, but this algorithm has a disadvantage in that it has long waiting times.

Fair scheduling is a method of assigning resources to requests in which the requests are distributed equally such that all requests get an average share of resources over time. The available Center Processing Unit (CPU) is divided initially among the groups, then among the users within each group. The requests into each pool (group) are scheduled using either fair scheduling or FIFO scheduling. The fair scheduler can limit the number of running requests per user and per pool. The key goal of the fair scheduler is to run small requests quickly in case the large requests are running [23].

The objectives of the fair-share scheduler are to ensure fairness, fast response time, and load spreading without making any request wait for too long.

The FCFS is implemented if all requests have the same weight, which means all processes in the requests queue are given time in the form of a time slice that increases when the weight increases. The average wait time for Weighted Round Robin (WRR) is better than for RR [24].

\section{E. Problem Definition}

Electricity is defined as a secondary source of energy that uses other primary sources, like coal and wind, that are increased during that use. But the use of electricity increases every year by consumers due to the ease of which it moves from the producer's position (power plant) among long distances to the consumption position.

Therefore, the electricity grid traditionally was proposed and built to give and distribute the energy service. Now, though, consumers consume large amounts of energy to operate several appliances, such as microwaves, washers, lights, Coffee Maker, and more, at the same time, and the cost of electricity is dynamic at peak and off-peak pricing.

For this reason, smart grids are being developed to manage energy consumption by reducing energy consumption and its cost and, as a result, the energy bill.

Many approaches have been implemented to manage energy consumption. Most of these approaches helped to reduce the total energy cost, but according to our knowledge, much saving can be accomplished with an improved approach.

\section{F. Paper Objectives}

In this paper, a set of goals were achieved, as are listed below:

1) To allow for monitoring and controlling in to reduce the amount of energy consumption of home appliances.

2) To reduce the cost of energy consumption and power interruption periods, and after that, reduce the energy bill for the customer.

3) To reduce peak demand, which will also help lower electricity rates.

\section{G. Paper Organization}

This paper is composed of five sections. After the introduction section, we list the related works for this paper in Section II. Section III presents the methodology and the system model of this paper. In Section IV, the experiments and results are discussed. Section $\mathrm{V}$ presents the conclusion of the suggested work and future work.

\section{RELATED WORKS}

In the literature, the increasing demand for electricity in the grid and the need to manage the energy consumption has been studied in several works from 2009 until now. 
Many approaches that have been proposed and implemented to manage energy consumption to decrease the rate of total energy consumption and reduce the total energy cost in energy bills. We present in the following the most important papers discussing this issue, and then, we present a summary and discussion of the most important papers related directly to our work.

The work in [24] proposed an optimal and automatic residential energy consumption scheduling framework with the goal of decreasing the cost of the energy bill and minimizing the waiting time for the operation of each device. The authors studied the consumption during the period between September 1, 2009, and December 31, 2009 (122 days; four months). The number of devices used each day varied from 10 to 25 . The devices were divided into two parts: fixed-consumption devices, such as electric stove, lighting, heating, refrigerator-freezer, and devices with a varying consumption energy rate, such as dishwasher, clothes washer, clothes dryer, and PHEV. The results showed that their technique reduced the user's cost along with the peak-toaverage ratio in the load demand.

In [14], the authors employed TOU-aware energy management in a smart home with a wireless sensor home area network that affected the peak load to reduce the energy bills. The rate of electricity was different in each on-peak, moderate-peak, and off-peak hours. The smart grids were divided into three parts, smart meters, home gateway, and user devices, and the devices could collaborate to reduce the consumer demand to decrease the energy bills and the load on the grid.

This application uses wireless communication between user devices and sensor network; the devices also communicate with an energy management unit (EMU), which manages the user requests by scheduling the duration of devices to off-peak hours or provides the use of local energy, if available. The residential energy management application is an important component of the smart grid that combines the Information and Communication Technologies (ICT) to the traditional power grid, and the communication among devices and energy uses Zigbee with IEEE 802.15.4 standard with short-range wireless links.

The simulator used was implemented in $\mathrm{C}++$, and the user request was modeled as a Poisson process. The interarrival rate for off-peak hours had a negative exponential distribution with a mean of 12 hours, while in the peak hours, the mean was 1 hour. The devices used were a washer, dryer, dishwasher, and coffee maker, which deployed in the peak winter period from 7 to 11 am and from 5 to $9 \mathrm{pm}$ and the mid-peak hours from 11 am to $5 \mathrm{pm}$.

The simulation ran between 10 and 210 days, and the maximum delay chosen was 24 hours. The performance metrics were taken (e.g., the peak load ratio, total payment of energy consumption, and delay by the users). The results showed a reduction in the user's sharing on the peak load by $30 \%$.

The authors in [18] presented a home energy management application that is used in a WSN. The sensor nodes are communicated by IEEE 802.15.4 and specify the performance metrics. The metrics are 1) delivery ratio (the ratio of the number of metrics received to the number sent) and 2) delay and packet delay variance for two forms (differential interval times and different network sizes).

The periods of time are divided into two interval times, depending on the load on the network. The first period is called the on-peak period, in which there is high loading on the network, and the other period is called the off-peak period, in which there is low loading on the network. When the load becomes a high load on the network, it is called an on-peak period, but when the load is low, the network it is off-peak.

In [13] they presented an application called in-Home Energy Management (iHEM) that uses WSNs, which employ smart devices. The message flow for iHEM is given in Fig. 3. When the consumer turns on the devices, it generates the start request (START-REQ) packet and sends it to the EMU, which communicates with the smart meter, which in turn gives the updated price information.

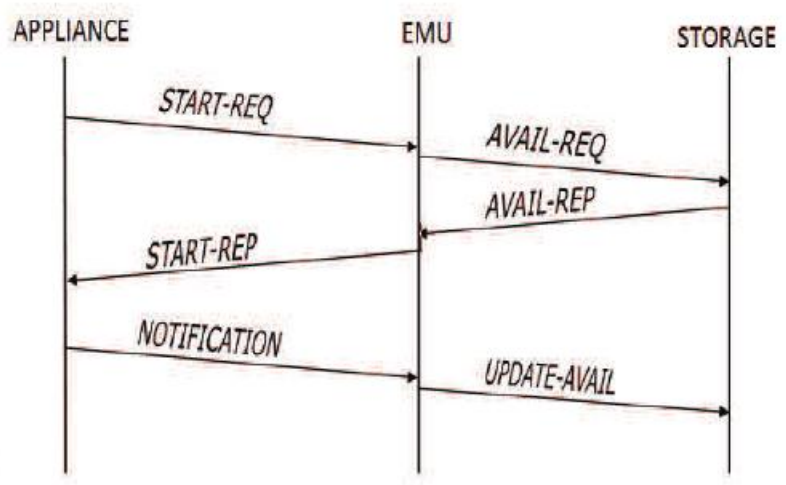

Fig. 3. Message flow for iHEM [13]

The EMU's role is to send the available request (AVAILREQ) packet to the energy units, which then retrieve the available amount of energy in the unit and return the available reply (AVAIL-REP) packet back to the requested EMU. The EMU determines the starting time of the devices and computes the waiting time, which is defined as the difference between the suggested and requested start time. Finally, the user decides whether to operate the device immediately or wait.

The simulator used was Qualnet (network simulator). The devices can be defined by two types: 1) a full-function device, such as a smart meter, and 2) a reduced-function device. The WSN is organized in this simulation using a cluster-tree topology, and the interval time is specified between periods (100s-300s). The numbers of the selected nodes are between 20 and 30 nodes. The results from this simulation showed that the delivery ratio increased for small size networks, which reached $85 \%$, while the end-to-end delay decreased. Therefore, the performance of the WSN was better for smaller networks.

The authors in [16] presented an evaluation of the performance of iHEM, in which they showed the effectiveness of iHEM and the Optimization-Based Residential Energy 
Management (OREM) scheme. OREM reduces users' energy consumption, while iHEM is able to achieve more objectives, such as reducing the share of the devices in energy bills, reducing the contribution to the peak load, and reducing carbon emission.

Performance was measured by a number of scenarios: local energy generation, iHEM with priority, and iHEM with RTP. There are three components to iHEM: EMU that communicates with devices, a smart meter, and a storage unit. It also employs WSNs for communication through a ZigBee protocol. The simulation period was extended for seven months (from 20 to 210 days).

The researchers applied the iHEM simulation through Microsoft Visual studio $\mathrm{C}++$, where the interarrival time between two requests is a negative exponential distribution with a mean of 12 hours while the mean is 2 hours for both the morning and evening periods. Four devices were used in this simulation (washer, dishwasher, dryer, and Cofee Maker), and the delay accepted in the OREM was 12 hours. The simulation time was between 20 to 210 days for each OREM and iHEM scheme.

The results reduced the expenses of the consumers, compared to the case without energy management, and in all scenarios, the total contribution of the devices to the energy bill decreased when compared without priority, feed-in (local generation), and to the TOU pricing scheme.

In [13], the authors developed the Energy Management and Monitoring system (EMM), which manages the power in buildings with a Building Energy Management System (BEMS). EMM contains an EMM client placed in the building with two forms of interfaces (wired and wireless) to gather the energy metering and sensor data through the Internet by many sensors and then sends it to the EMM server installed in the EMM center and linked with smart meters to compute the energy consumption.

The EMM system is proposed to provide Energy Management Service (EMS) functions, select energy resources with a low price, reduce unnecessary loads, and control the battery of PHEVs that are interworking with a smart grid.

The work in [8] proposed an Optimum Load Management (OLM) technique for RTP that utilizes the communication infrastructure of the future smart grid that will enable the consumer to balance between energy bills and their economic situation. The aim of this scheme is to reduce energy consumption cost, and the results showed high potential by reducing the energy bill by $8-22 \%$.

The authors in [8] presented details of the various Home Energy Management schemes (HEMs), which aim to reduce the peak demand, an average ratio (PAR) and increase savings. That makes the grid smarter and faster in making decisions.

The demand curve and flat pricing rates scenario in the traditional power grid shows that the load demand during peak periods is very high vs. off-peak periods. HEMs enable Demand Side Management systems (DSM) and Demand
Response (DR).

There are different techniques for energy management in the smart grid:

1) OREM aims to manage the energy consumption by scheduling home devices, and it specifies the maximum delay for each device as equal to the length of two-time slots.

2) The iHEM system uses smart devices, a central EMU, and WSNs for communication purposes through ZigBee protocol, and there are two types of devices: Full-Function and Reduced-Function devices. Full-function devices are interconnected in a mesh topology, and Reduced-Function devices are interconnected in a star topology. That aims to manage the home energy by shifting the load to off-peak periods.

The application works when the consumer presses the start button of the device, and the device generates a data packet that is sent to the EMU. The EMU communicates with the smart meter, and local generation units provide the price information. The EMU schedules the time of the device from this information.

The results showed that the sharing of the device to the total load was reduced during peak hours, and the peak load was reduced up to $5 \%$.

The authors in [26] studied the development of the smart residential load simulator with a user-friendly graphical interface that aims to achieve easy study of energy management systems in smart grids by simulating the on-off decisions of residential devices. For this study, they used a specific tool based on Matlab Simulink-GUID toolbox available at www.power.uwaterloo.ca. Appliances used in this study were thermostats, air conditioners, furnaces, water heaters, refrigerators, stoves, dishwashers, clothes washers, dryers, lights, and pool pumps, as well as wind, solar, and battery.

The authors in [21] presented a new scheduling method to smooth the demand situation of each house to reduce the energy prices by using a genetic algorithm, which controls the occurrence time of devices and coordinates the groups to set optimization of each group at the same time.

The objectives of the proposed method were to shift the peak demand, control a wide range simultaneously, and reduce the utility bill. The results showed that the proposed method can reduce electric costs by $4.71 \%$.

The authors in [10] studied the problem of the increased level of demand response management in the smart grid called offline scheduling. The objective was to be able to schedule all requests with a minimum total electricity cost. They proposed a polynomial time offline algorithm to achieve the optimal solution, and it was able to optimize the time complexity to $\mathrm{O}(\mathrm{n} \mathrm{T} \log \mathrm{n})$, where the time complexity before the optimization is $\mathrm{O}(\mathrm{n} 2 \mathrm{~T})$.

A simulator was implemented by using Python for a sixhour timeframe and divided into a sequence number of time slots, and it is available online at [23]. 
The work in [17] proposed the Appliance Coordination (ACORD) scheme for smart grids that allows flexibility in the start time for home devices. The main goal of the ACORD scheme is to shift devices' start time to off-peak hours when the consumer's desired start time falls between peak hours. The scheme uses the in-home WSN to relay the data between the coordinator and the different devices in the home. The architecture for the ACORD scheme is given in Fig. 4. When the user operates the device by the start button, it generates a START-REQ packet that contains the desired on duration cycle of the device (e.g., washing cycle of the washer) and the packet is sent to the EMU by the WSN.

Once the EMU receives the START-REQ packet, it schedules the available start time, if no hard start time is requested, after communicating with the smart meter to check the TOU rate and peak hour information. In a large house environment, the EMU may be physically far away from the appliances and not reachable on one hop by all devices. Thus, multi-hopping is required for message delivery.

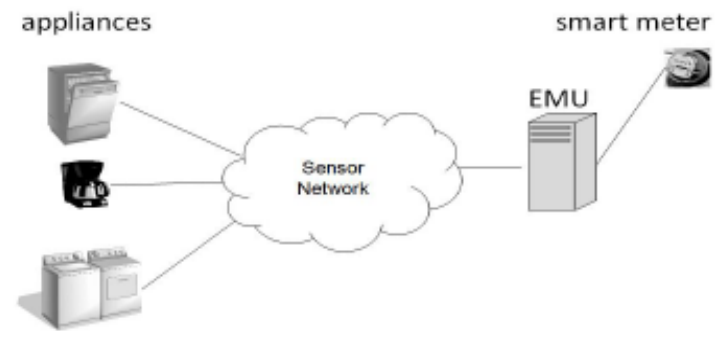

Fig. 4. The architecture for the ACORD scheme [17]

The waiting time or the scheduled start time is sent back to the consumer by the START-REP packet and set to zero if the consumer requests a hard start time or the desired start time is in off-peak hours and no other requests are scheduled on that time. The consumer's final decision is sent back to the EMU in notification packets, using the decision in the reserve time slot for the device

The researchers tested the performance of the scheme using simulation. They used two different load scenarios, high and low consumer activity cases. In the high- and low-activity cases, the interarrival times between the two requests were assumed to be a negative exponential distribution with means of 6 and 48 hours. The devices used included a washer, dryer, dishwasher, and coffee maker. The peak hours chosen were between 7 and $11 \mathrm{am}$ and 5 and $9 \mathrm{pm}$ in the winter on weekdays, and the maximum acceptable delay was 10 hours. The performance metrics used were the total cost saving in dollars and the number of lost requests in the sensor network. The results showed that the total contribution of the devices to the energy bill was $\$ 47$ of the consumer requests at the period.

The authors in [15] proposed the ACORD-FI scheme as an improvement of the ACORD scheme proposed in [17]. The main assumption here is that the device can manage the user requests and the energy is generated locally to reduce the sharing of the devices and provide savings on the energy bill. The scheme uses the in-home WSN to relay the data between the coordinator and the different devices in the home.
They tested the performance of the scheme using simulation. They used two different load scenarios, high- and low-activity cases. The interarrival times between two requests were assumed to be negative exponential distribution with means of 6 and 48 hours. The devices used included a washer, dryer, dishwasher, and coffee maker. The peak hours chosen were between 7 and 11 am and 5 and $9 \mathrm{pm}$ in the winter weekdays, and the maximum acceptable delay was 10 hours. The performance metrics used were the total cost savings in dollars and the number of lost requests in the sensor network. The results showed an improvement over ACORD by a rate of $\$ 37$ as a total contribution of devices to the energy.

In [23], the authors proposed a new energy scheduling algorithm to minimize the expenses of a customer energy bill. The proposed algorithm takes into account the uncertainty in household appliances and the irregular renewable energy generation. It also takes into consideration the variable power generation from renewal resources (e.g., solar, air, etc.) and the capacity-limited energy storage in attached batteries.

The proposed scheme was claimed to achieve up to a $45 \%$ cost reduction compared to traditional scheduling algorithms. Also, this proposed scheme was claimed to be able to generate a scheduling solution in 10 seconds, which is fast enough for home appliances applications.

In [24], the authors proposed a dynamic scheduling scheme that depends on the idea of optimal portfolio selection to generate a user's energy consumption history, called a weighted graph. By using this weighted graph, the scheme can detect the user's need of energy close to the optimal need. The performance of the proposed scheme is evaluated with different performance metrics-peak-demand, demand variation, energy cost, and the utility of the customers. Simulation results showed that the proposed dynamic scheduling scheme, D2S, yielded improved performance compared to the existing ones of no scheduling and static scheduling.

In [25], the authors proposed a power scheduling scheme formulated as an optimization problem that includes integer and continuous variables. An optimal scheduling strategy is obtained by solving the optimization problem. The proposed work assumed that consumers have two types of appliances. The first type of appliances has a flexible starting time and works continuously with fixed power.

The second type of appliances works with flexible power in a predefined working time. At the same time, the consumers can adjust the starting time of the first type of appliances or reduce the power consumption of the second type of appliances to reduce the payments. However, this also will incur discomfort to the consumers. As claimed, the simulation results achieved the desired trade-off between the payments and the discomfort by solving the optimization problem.

Table 2 presents a summary of works related directly to ours and shows the goal of the reference, techniques used, main results, simulator used, period used, and the number of appliances used. 
TABLE II. A COMPARISON BETWEEN THE DEPLOYMENT TECHNIQUES THAT HAVE BEEN USED IN RELATED WORKS

\begin{tabular}{|c|c|c|c|}
\hline $\begin{array}{l}\text { Reference number and } \\
\text { name }\end{array}$ & Goal of the reference & Technique used & Results \\
\hline $\begin{array}{l}\text { [8] Home Energy } \\
\text { Management Systems in } \\
\text { Future Smart Grids }\end{array}$ & $\begin{array}{l}\text { Enable the consumer to } \\
\text { balance between energy } \\
\text { bills and economic } \\
\text { situation. }\end{array}$ & $\begin{array}{l}\text { Optimum Load } \\
\text { Management } \\
\text { (OLM) technique. }\end{array}$ & $\begin{array}{l}\text { Reduced the energy } \\
\text { bill by } 8-22 \% \text {. }\end{array}$ \\
\hline $\begin{array}{l}\text { [8] Home Energy } \\
\text { Management Systems in } \\
\text { Future Smart Grids }\end{array}$ & $\begin{array}{l}\text { Reduce the peak demand, } \\
\text { average ratio (PAR), and } \\
\text { increase savings. }\end{array}$ & $\begin{array}{l}\text { Home Energy } \\
\text { Management } \\
\text { schemes (HEMs). }\end{array}$ & $\begin{array}{l}\text { Reduced the peak load } \\
\text { up to } 5 \% \text {. }\end{array}$ \\
\hline $\begin{array}{l}\text { [9] Scheduling for } \\
\text { Electricity Cost in Smart } \\
\text { Grid }\end{array}$ & $\begin{array}{l}\text { Schedule all requests with } \\
\text { minimum total electricity } \\
\text { cost. }\end{array}$ & $\begin{array}{l}\text { Polynomial time } \\
\text { offline algorithm. }\end{array}$ & $\begin{array}{l}\text { Achieved the optimal } \\
\text { solution and was able } \\
\text { to optimize the time } \\
\text { complexity to O (n T } \\
\log \mathrm{n} \text { ). }\end{array}$ \\
\hline $\begin{array}{l}\text { [10] Proactive energy } \\
\text { management system } \\
\text { architecture interworking } \\
\text { with smart grid }\end{array}$ & $\begin{array}{l}\text { Manage the power in } \\
\text { buildings with Building } \\
\text { Energy Management } \\
\text { Systems (BEMS). }\end{array}$ & $\begin{array}{l}\text { Energy } \\
\text { Management and } \\
\text { Monitoring (EMM) } \\
\text { system. }\end{array}$ & $\begin{array}{l}\text { Reduced unnecessary } \\
\text { loads and controlled } \\
\text { the battery of PHEVs } \\
\text { that were interworking } \\
\text { with the smart grid. }\end{array}$ \\
\hline $\begin{array}{l}\text { [11] TOU-Aware Energy } \\
\text { Management and Wireless } \\
\text { Sensor Networks for } \\
\text { Reducing Peak Load in } \\
\text { Smart Grids }\end{array}$ & $\begin{array}{l}\text { Achieve efficient use of } \\
\text { green energy, increase } \\
\text { automation in distribution, } \\
\text { and enable residential } \\
\text { energy management. }\end{array}$ & $\begin{array}{l}\text { Time of Use } \\
\text { (TOU)-aware } \\
\text { energy } \\
\text { management. }\end{array}$ & $\begin{array}{l}\text { Reduction in the } \\
\text { consumer's the } \\
\text { contribution on the } \\
\text { peak load by } 30 \% \text {. }\end{array}$ \\
\hline $\begin{array}{l}{[12] \text { Using Wireless Sensor }} \\
\text { Networks for Energy- } \\
\text { Aware Homes in Smart } \\
\text { Grids }\end{array}$ & $\begin{array}{l}\text { Reduce the total cost of the } \\
\text { energy bill and provide } \\
\text { more savings on the energy } \\
\text { bill. }\end{array}$ & $\begin{array}{l}\text { Appliance } \\
\text { Coordination with } \\
\text { Feed In (ACORD- } \\
\text { FI) scheme. }\end{array}$ & $\begin{array}{l}\text { Improved total } \\
\text { contribution of devices } \\
\text { to the energy bill to } \\
\$ 37 \text {. }\end{array}$ \\
\hline $\begin{array}{l}\text { [13] Wireless Sensor } \\
\text { Networks for Cost- } \\
\text { Efficient Residential } \\
\text { Energy Management in the } \\
\text { Smart Grid }\end{array}$ & $\begin{array}{l}\text { Evaluate the performance } \\
\text { of In-Home Energy } \\
\text { Management application } \\
\text { (iHEM). }\end{array}$ & $\begin{array}{l}\text { iHEM and } \\
\text { Optimization-Based } \\
\text { Residential Energy } \\
\text { Management } \\
\text { (OREM) scheme. }\end{array}$ & $\begin{array}{l}\text { Reduced the } \\
\text { consumer's expenses, } \\
\text { compared with the } \\
\text { case without energy } \\
\text { management. }\end{array}$ \\
\hline $\begin{array}{l}{[14] \text { Wireless Sensor }} \\
\text { Networks for Smart Grid } \\
\text { Applications }\end{array}$ & $\begin{array}{l}\text { Achieve the performance } \\
\text { of the wireless sensor } \\
\text { networks (WSN) under } \\
\text { varying interarrival times } \\
\text { and varying network sizes. }\end{array}$ & $\begin{array}{l}\text { A home energy } \\
\text { management } \\
\text { application. }\end{array}$ & $\begin{array}{l}\text { Increased delivery } \\
\text { ratio for small-size } \\
\text { networks that reached } \\
85 \% \text { while the end-to- } \\
\text { end delay decreased. }\end{array}$ \\
\hline $\begin{array}{l}\text { [16] Distributed Demand } \\
\text { Scheduling Method to } \\
\text { Reduce Energy Cost in } \\
\text { Smart Grid }\end{array}$ & $\begin{array}{l}\text { Shift peak demand, control } \\
\text { a wide range } \\
\text { simultaneously and reduce } \\
\text { utility bill. }\end{array}$ & $\begin{array}{l}\text { Distributed Demand } \\
\text { Scheduling method. }\end{array}$ & $\begin{array}{l}\text { Reduced electricity } \\
\text { costs by } 4.71 \% \text {. }\end{array}$ \\
\hline $\begin{array}{l}\text { [18] Optimal Residential } \\
\text { Load Control with Price } \\
\text { Prediction in Real-Time } \\
\text { Electricity Pricing } \\
\text { Environments }\end{array}$ & $\begin{array}{l}\text { Differentiate between } \\
\text { minimizing the payment } \\
\text { and minimizing the waiting } \\
\text { time for the operation of } \\
\text { each device. }\end{array}$ & $\begin{array}{l}\text { Optimal and } \\
\text { automatic } \\
\text { residential energy } \\
\text { consumption } \\
\text { scheduling } \\
\text { framework. } \\
\end{array}$ & $\begin{array}{l}\text { Reduction in user's } \\
\text { payments and in peak- } \\
\text { to-average ratio in } \\
\text { load demand. }\end{array}$ \\
\hline $\begin{array}{l}\text { [19] Development of a } \\
\text { Smart Residential Load } \\
\text { Simulator for Energy } \\
\text { Management in Smart } \\
\text { Grids }\end{array}$ & $\begin{array}{l}\text { Achieve easy study of } \\
\text { energy management } \\
\text { systems in smart grids. }\end{array}$ & $\begin{array}{l}\text { Development of the } \\
\text { smart residential } \\
\text { load simulator. }\end{array}$ & $\begin{array}{l}\text { Reduced the peak load } \\
\text { in dynamic pricing } \\
\text { (delay the demand to } \\
\text { the periods of the low } \\
\text { electricity price). }\end{array}$ \\
\hline $\begin{array}{l}\text { [25] Wireless Sensor } \\
\text { Networks for Domestic } \\
\text { Energy Management in } \\
\text { Smart Grids }\end{array}$ & $\begin{array}{l}\text { Shift devices start time to } \\
\text { off-peak hours. }\end{array}$ & $\begin{array}{l}\text { Appliance } \\
\text { Coordination } \\
\text { (ACORD) scheme. }\end{array}$ & $\begin{array}{l}\text { Improved total } \\
\text { contribution of devices } \\
\text { to the energy bill to } \\
\$ 47 .\end{array}$ \\
\hline
\end{tabular}

\section{METHODOLOGY AND SYSTEM MOdEL}

In this section, we propose two novel scheduling schemes to enhance the ACORD-FI scheme [15]. The proposed techniques are based on the non-preemptive and preemptive scheduling schemes, both implemented on the Giving Waiting Time and the Priority of Devices approaches

\section{A. System Models}

1) Non-preemptive scheduling scheme (ACORD-FI): Before discussing our system models, we will discuss the scheme's steps of using on- and off-peak hours.

The ACORD-FI steps: 
- Step 1: Define all parameters that will be used in the simulation.

- Step 2: Create the current queue as a linked list, and add the events or appliances into the current queue with two parameters. The first parameter is the type of event (start or stop), and the second is the timestamp of the event or appliance, which is computed by the Poisson process model [19], where the interarrival time between two requests is a negative exponential distribution with random numbers of the timestamp given the event or appliance using the following equations:

Where the function returns a random number between 0 and 1 ,

\section{Generate_RandomNumbers $=\operatorname{rand}() /\left(R A N D \_M A X+1\right)$}

Exponential_Distrbution $=$

- time ${ }^{*} \log ($ Generate_RandomNumbers)

where the function is the negative exponential distribution and the time is the interarrival time between requests.

- Step 3: Check if the timer is less than the simulation, time where the value of the timer in the beginning is zero.

- Step 4: Return the event with the smallest timestamp.

- Step 5: Select the smallest timestamp of the event in the current queue. If the case is a start event, schedule the stop event for this event in the current queue. If the case is a stop event, calculate the energy consumption and the cost of energy consumption of the appliances through the period using the following equations, and schedule the start event for this event in the current queue.

Energy_Consumption $=($ Power $*$ Dtime $) / 100$

where power is the energy consumption of the appliance in watts and Dtime is the time the appliance takes to finish the work. Divide the result by 1000 to convert it to kilowatts.

$$
\begin{aligned}
& \text { Cost_Energyconsumption }()= \\
& \text { Energy_Consumption } * \cos t_{\text {_on }}-\text { or }- \text { off }- \text { Peakhours }() / 1000
\end{aligned}
$$

The energy consumption in (3) is computed kilowatts, and cost_on-or-off-Peakhours is the price of the period in the onor off-peak hours in cents for Ontario and fills for Jordan. The total cost is calculated in Canadian dollars.

2) Non-preemptive scheduling scheme (ACORD-FI): In this scheme, without using on- and off-peak hours, we change the equation for calculating the cost of energy consumption used with on- and off-peak hours (4).

The ACORD-FI steps are the same as with using the onand off-peak hour scheme's steps, except it differs when calculating the cost of the appliances' energy consumption through the period using the following equation:

$$
\begin{aligned}
& \text { Cost_Energyconsumption }()= \\
& \text { Energy_Consumption } * \cos t_{\text {_on }}-\text { and }- \text { off }- \text { Peakhours }() / 1000
\end{aligned}
$$

where the energy consumption is computed by (3) in kilowatts, and the cost_on-and-off-Peakhours is the average of prices of both periods where the prices are in Ontario or in Jordan. The total cost is calculated in Canadian dollars.

We are going to enhance the effectiveness (reducing energy consumption and total cost of energy consumption) of the non-preemptive scheduling scheme using two schemes: a preemptive scheduling scheme by giving priority (weight) for several appliances and a preemptive scheduling scheme by giving waiting time (delay).

\section{B. Proposed Schemes}

1) Appliances Coordination by Giving Waiting Time (ACORD-WT) scheme: The preemptive scheduling scheme is considered one of the most effective scheduling techniques to reduce energy consumption and the total cost of the energy consumption.

This scheme differs from the ACORD-FI scheme [15] by developing a new technique for choosing the best event. The ACORD-FI scheme [15] depends on choosing the event with the smallest timestamp, unlike the ACORD-WT scheme for some appliances, which depends on choosing the event with the smallest timestamp and amount of energy required.

The ACORD-WT scheme is an energy management scheme, and it is an enhancement of the ACORD-FI by including scheduling algorithms that give waiting time to several devices.

In the ACORD-WT scheme, the user may operate a device at any time regardless of the peak hours (on-peak hours or offpeak hours). When the user operates a device, the device communicates with the EMU to check for the smallest timestamp for devices. The interval between the start time and the requested start time is computed by the EMU is called the waiting time, and it is sent back to the device. The message flow for the ACORD-WT scheme is given in Fig. 5. The device generates a START-REQ packet and sends it to the EMU. The START-REQ packet contains the type of request and the device cycle.

When the EMU receives the START-REQ packet, the EMU links with the storage unit by generating an AVAILREQ packet and retrieves the amount of the available energy. The storage unit replies with the amount of available energy to the EMU with an AVAIL-REP packet.

After receiving the AVAIL-REP packet, the EMU specifies the starting time of the device by using Algorithm 1, as shown in Fig. 6. The user decides whether to start the device or wait, depending on the waiting period for each device. The user's decision is sent back to the EMU with a notification (NOTIFICATION) packet.

The EMU sends an update available (UPDATE-AVAIL) packet to the storage unit to update the amount of available energy on the unit after receiving the user's decision. The algorithm of the ACORD-WT scheme (Algorithm 1, Fig. 6) works as follows. The EMU first checks if the stored energy is available, and the devices will be operated immediately; otherwise, the devices will be operated depending on the waiting period given for each device. 


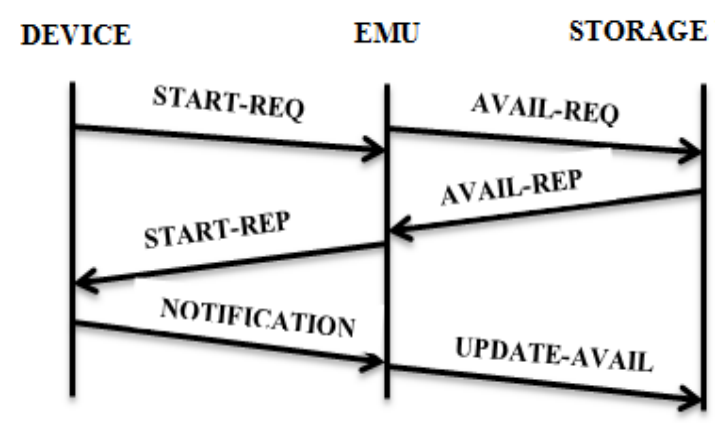

Fig. 5. Message flow for ACORD-WT scheme

In the below the specification of the scheme steps:

The first five steps are the same as the ACORD-FI scheme [15], but it differs in phase seven after we select the smallest timestamp of the event in the current queue. If the case is a start event, we calculate the energy consumption, which is computed by (3), and the energy required by adding the value of the current energy with the value of the event's energy consumption using the following equations:

\section{Required_Energy = \\ Current_Energy + Energy_Consumption()}

After we check if the amount of energy required is less than or equal to the amount of the energy threshold, where the energy threshold is equal to $2.47 \mathrm{kWh}$ when using four devices and $8.16 \mathrm{kWh}$ when using six devices, and if the condition is true, we schedule the stop event for this event in the current queue. We then add the value of energy consumption to the current energy, where the value of the current energy, in the beginning, is zero, using the following equations:

\section{Current_Energy $=$ \\ Current_Energy + Energy_Consumption()}

But if the condition is not true, we remove the event from the current queue and schedule the stop event for this event in the current queue by changing the timestamp parameter, which equals the negative exponential distribution [19] of the timestamp computed by (2) with the value of the current timer.

In the stop case, we calculate the energy consumption and the cost of appliances' energy consumption through the period by using (3) and (4), and then we subtract the value of energy consumption from the value of the current energy using the following equation, (7), and schedule the start event for this event in the current queue. The total cost is calculated in Canadian dollars for Ontario and Jordan. The ACORD-WT algorithm is given in Fig. 6.

$$
\begin{aligned}
& \text { Current_Energy }= \\
& \text { Current_Energy - Energy_Consumption }()
\end{aligned}
$$

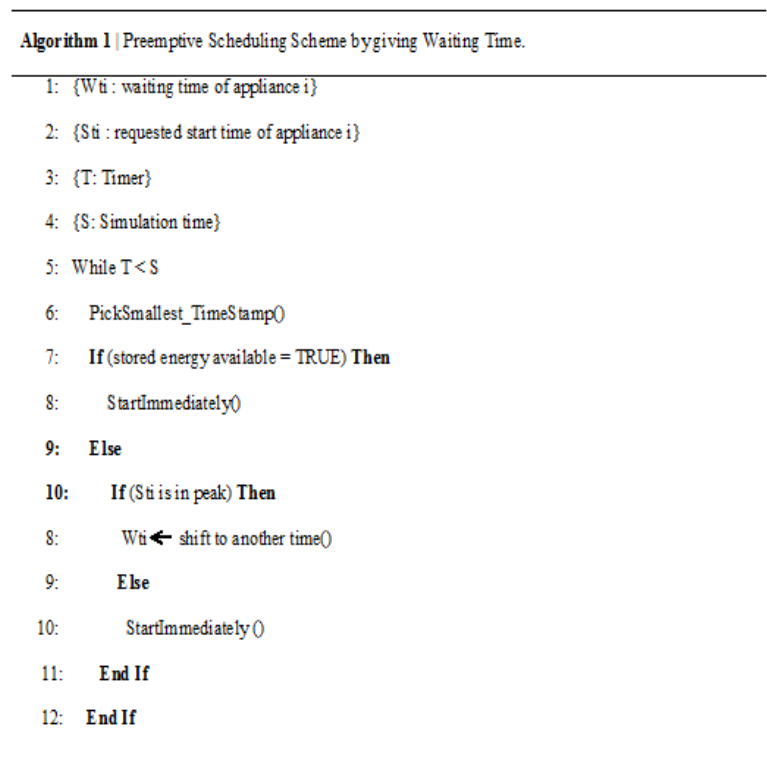

Fig. 6. Appliances Coordination by Giving Waiting Time scheme (ACORDWT) algorithm

2) Appliances Coordination by Giving Priority (ACORD$P)$ scheme: The implementation of this scheme differs from the previous schemes in scheduling the event and the technique for selecting the best event.

The ACORD-P scheme for some appliances depends on choosing the event with the smallest timestamp, checking if the current queue is empty or not, and the amount of energy required.

The ACORD-P scheme is an energy management scheme and is proposed to enhance the ACORD-FI, which includes the locally generated energy with energy management decisions by giving priority to some devices.

In the ACORD-P scheme, the user may operate a device at any time regardless of the peak hours (on-peak hours or offpeak hours). When the user operates a device, the device communicates with the EMU to check for the smallest timestamp for devices.

The interval between the start time and the requested start time, called the waiting time, is computed by the EMU and sent back to the device. The device generates a START-REQ packet and sends it to the EMU. The START-REQ contains the type of request, the device cycle, and the weight of the device.

When the EMU receives the START-REQ, the EMU communicates with the storage unit by generating an AVAILREQ and retrieves the amount of the available energy. The storage unit replies with the amount of available energy to the EMU with an AVAIL-REP.

After receiving the AVAIL-REP, the EMU determines the starting time of the device by using Algorithm 2, as shown in Fig. 7. 
The user decides which device to start or wait, depending on the rank of priority (the device that has maximum weight is the first in the operating list). The user's decision is sent back to the EMU with a NOTIFICATION.

The EMU sends an UPDATE-AVAIL to the storage unit to update the amount of available energy on the unit after receiving the user's decision.

The algorithm of ACORD-P scheme (Algorithm 2, Fig. 7) works as follows. The EMU, in the beginning, checks if the stored energy is available, and the devices will be operated immediately, and the amount of energy in the storage unit will be updated; otherwise, the devices will be operated depending on the rank of priority (weight) for each device.

The following are the specifications of the scheme steps:

- Step 1: Define all the parameters used in the simulation.

- Step 2: Create the current queue as a linked list and array called "running appliances array," and then add the events or appliances into the current queue with two parameters. The first parameter is a type of event (start or stop), and the second is a timestamp of an event or appliance that is computed by the Poisson process model [19], where the interarrival time between two requests is a negative exponential distribution with random numbers of the timestamp given of the event or appliance, which is computed by (2).

- Step 3: Check if the timer is less than simulation time.

- Step 4: Check if the current queue is empty or not.

- Step 5: Return the event with the smallest timestamp.

- Step 6: Select the smallest timestamp of the event in the current queue.

- Step 7: In the current queue, we check if the case is a start event, and we calculate the energy consumption, which is computed by (3), and energy required, which is computed by (6).

After that, we check if the amount of energy required is less than or equal to the amount of the energy threshold, where the energy threshold is equal to $2.47 \mathrm{kWh}$ when using four devices and $8.16 \mathrm{kWh}$ when using six devices. If the condition is true, we schedule the stop event for this event in the current queue, and then we add the value of energy consumption to the current energy, where the value of the current energy in the beginning is zero, which is computed by (7).

- Step 8: Return the maximum weight for all events in the running appliances array.

- Step 9: Select the maximum weight of the event in the running appliances array.

- Step 10: In the array, if the case is a start event, we calculate the energy consumption, which is computed by (3), and the energy required, which is by (6).

After that, we check if the amount of energy required is less than or equal to the amount of the energy threshold, where the energy threshold is equal to $2.47 \mathrm{kWh}$ when using four devices and $8.16 \mathrm{kWh}$ when using six devices. If the condition is true, we schedule the stop event for this event in the current queue, and then we add the value of energy consumption to the current energy, where the value of the current energy in the beginning is zero, which is computed by (7). But if the condition is not true, we remove the event from the current queue and schedule the start event in the running appliances array with three parameters. The first parameter is the type of event (start or stop). The second parameter is a timestamp of the event or appliance computed by the Poisson process model [19], where the interarrival time between two requests is a negative exponential distribution with random numbers of the timestamp given of the event or appliance using (2). The third parameter is the weight, where the weights are specified by the questioner for the appliances washer, dishwasher, dryer, Cofee Maker, PHEV, and AC, and the weight for each device is $9,4,5,8,6$, and 7 , respectively.

In the stop case, we calculate the appliances' energy consumption and cost of energy consumption through the period by using (3) and (4) and then subtract the value of energy consumption from the value of the current energy in (8) and schedule the start in the running appliances array. The total cost is calculated in Canadian dollars for Ontario and Jordan. The ACORD-P algorithm is given in Fig. 7.

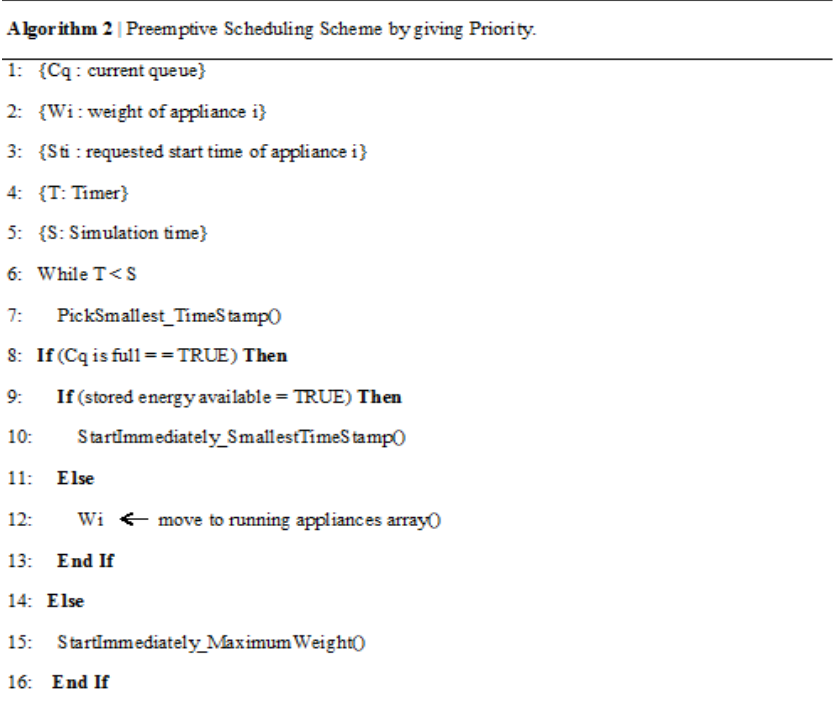

Fig. 7. Appliances Coordination by Giving Priority (ACORD-P) scheme algorithm

Until the current queue becomes empty, we go from working on the running appliances array, to select the best event, depending on the maximum weight from all events. After that, we select the maximum weight of the event in the running appliances array. If the case is a start event, we update with stop event for this event in the running appliances array. If the case is a stop event, we calculate the energy consumption and the cost of the energy consumption of the appliances through the period in (3) and (4), and we update the start event with the stop for this event in the running appliances array. The total cost is calculated in Canadian dollar for Ontario and Jordan. 
3) Appliances coordination by adding photovoltaic ( $P V)$ power source: In this paper, we suggest the use of a solar photovoltaic (PV) power supply. One solar panel with two hours of effective energy generation in winter will generate $350 \mathrm{w}$, and the feed-in tariff rates is 80.2 cents/kWh [15]. For our experiments with simple calculations, it is 28.07 cents/kWh for the Jordan tariff rate. During experiments, we used the stored power from the PV for the appliances' request in on-peak hours, and they were not used in off-peak hours. Therefore, we could guarantee full utilization benefits of the generated power. The on-peak time, as suggested, was between 7 and $11 \mathrm{am}$, which is the best time for the PV to renew the power in its batteries for future use.

The scenario used during experiments is as follows:

When the appliance (event) request arrives at the scheduling system, it checks if this request is in on-peak time. If yes:

- The system checks the energy amount of power needed and the available stored power from the PV. If it is enough, it immediately will start the event.

- If the energy amount stored is less than what is required, the system checks the end time of the event request, depending on appliance duration time. If this request ends at off-peak, the event starts immediately, also.

- If the energy amount is less than what is required and the end time is in on-peak, it moves this event to other scheduling algorithms used in the system.

If the appliance (event) request arrives at the scheduling system at off-peak time, the system will not do anything regarding the PV power stored and will run the event from the ordinary power using the other scheduling algorithms discussed previously.

\section{EXPERIMENTS AND RESULTS}

This section discusses the different experiments and results conducted to assess the performance of the proposed approaches discussed in Section III. We evaluate the performance by measuring the total cost of energy consumption for home appliances. The efficiency of the ACORD-FI scheme and the different proposed scheduling schemes have been tested based on the pricing in both Ontario and Jordan.

\section{A. Simulation Parameters and Assumptions}

Table 3 presents the main parameters of the simulation that applies to all schemes. All of these parameters and assumptions used are similar to those used in [15], except what applies to Jordan is proposed by us and based on the information gathered from the Ministry of Utilities in Jordan. The user requests are modeled as a Poisson process, during peak periods the interarrival times between two requests are negative exponentially distributed with a mean a 12 hours while during off-peak period, the interarrival times between two requests are negative exponentially distributed with a mean of 1 hour.
TABLE III. PARAMETERS USED FOR EACH SCHEME

\begin{tabular}{|l|l|l|}
\hline & Parameter & Value \\
\hline 1 & Simulation time & 210 days (approximately seven months). \\
\hline 2 & $\begin{array}{l}\text { Total number of } \\
\text { devices }\end{array}$ & $\begin{array}{l}\text { six devices: washer, dishwasher, dryer, } \\
\text { Cofee Maker, PHEV, AC }\end{array}$ \\
\hline 3 & Interarrival time & $\begin{array}{l}\text { Poisson process, with a negative } \\
\text { exponential distribution, during peak } \\
\text { periods with a mean of 12 hours and } \\
\text { during off-peak periods with a mean of 1 } \\
\text { hour. }\end{array}$ \\
\hline
\end{tabular}

The details of the simulated devices used have been discussed in detail in Section I, including the cycle duration and energy consumption. The peak hours are selected for both Ontario [27] and Jordan as determined in Table 4.

TABLE IV. TOU RATES IN ONTARIO AS OF 2011 AND JORDAN AS OF 2015

\begin{tabular}{|c|c|c|c|}
\hline & Period & Time & Rate \\
\hline Ontario & $\begin{array}{l}\text { On-peak } \\
\text { On-peak } \\
\text { Off-peak }\end{array}$ & $\begin{array}{l}\text { 7:00am to } \\
11: 00 \mathrm{am} \\
5: 00 \mathrm{pm} \text { to } \\
9: 00 \mathrm{pm} \\
9: 00 \mathrm{pm} \text { to } \\
7: 00 \mathrm{am}\end{array}$ & $\begin{array}{l}9.3 \mathrm{cent} / \mathrm{kWh} \\
9.3 \mathrm{cent} / \mathrm{kWh} \\
4.4 \mathrm{cent} / \mathrm{kWh}\end{array}$ \\
\hline Jordan & $\begin{array}{l}\text { On-peak } \\
\text { Off-peak }\end{array}$ & $\begin{array}{l}\text { 7:00am to } \\
11: 00 \mathrm{pm} \\
11: 00 \mathrm{pm} \text { to } \\
7: 00 \mathrm{am}\end{array}$ & $\begin{array}{l}62.71 / \mathrm{kWh} \\
52.66 / \mathrm{kWh}\end{array}$ \\
\hline
\end{tabular}

We simulate user requests between 10 days to 210 days (approximately seven months). The first 5 days from the period are spared for warm-up, and we present results as the average of 10 simulation runs.

Our simulator has been coded using in $\mathrm{C}++$ under Ubuntu version 12.04.4. The main performance measure used to compare between approaches is the total savings for cost of energy consumption in dollars.

\section{B. Results and Discussions}

In the following set of figures, we will show the different sets of comparisons between four and six devices, with and without delay, with and without priorities, and using PV with and without using proposed scheduling algorithms.

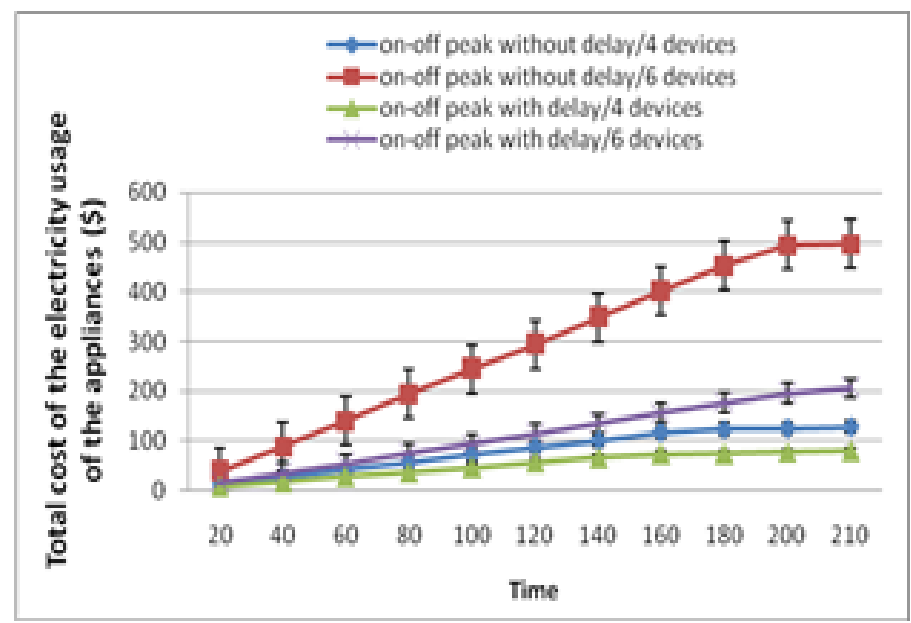

Fig. 8. The total cost of the electricity consumed by four and six devices with and without delay in Ontario 
Fig. 8 shows the relation between the time and total cost of energy consumption in dollars for different cases when on-off peak is used. In this set of experiments, we used the four and six devices as discussed in Section I. The two cases considered for each set of devices are with and without delay for the requests that came during the day. The same electricity prices are used for the province of Ontario. In either case of four or six devices, using the delay reduced the total cost since the requests were delayed for the off-peak periods whenever possible. For example, in the case of four devices without delay, the total cost for 210 days was $\$ 128.1$; however, the cost when a delay was used was reduced to $\$ 79.4$, resulting in savings of approximately $\$ 49$ for this period.

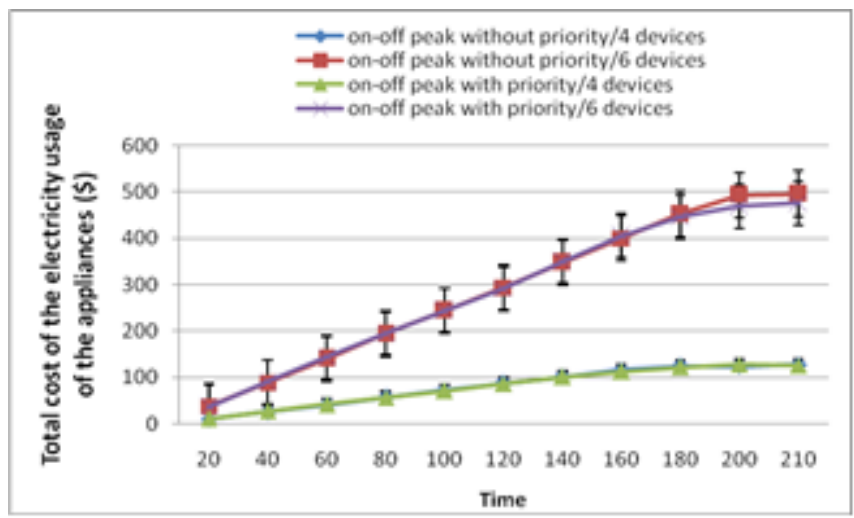

Fig. 9. The total cost of the electricity consumed by four and six devices with and without priority in Ontario

Fig. 9 shows the relation between the time and total cost of energy consumption in dollars for different cases when on-off peak is used. In this set of experiments, we used the four and six devices, as discussed in Section I. The two cases considered for each set of devices are with and without priority for the requests that came during the day. The same electricity prices were used for the province of Ontario. In either case of four or six devices, using the priority reduced the total cost since the requests were given priority to some appliances whenever possible. For example, in the case of four devices without priority, the total cost for 210 days was $\$ 128.1$; however, the cost when giving priority was reduced to $\$ 125.6$, resulting in a savings of approximately $\$ 3$ for this period.

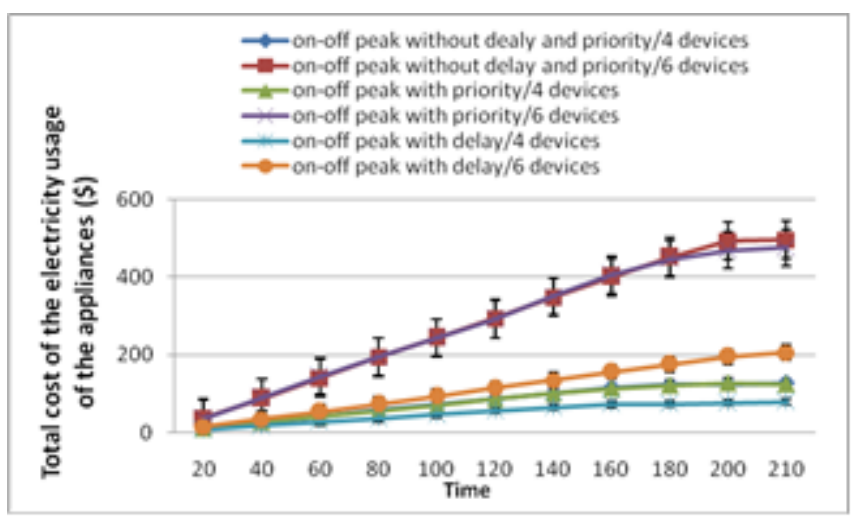

Fig. 10. The total cost of the electricity consumed by four and six devices with and without delay and priority in Ontario
Fig. 10 shows the relation between the time and total cost of energy consumption in dollars for different cases when onoff peak is used. In this set of experiments, we used the four and six devices as discussed in Section I. The three cases considered for each set of devices are with and without delay and priority for the requests that came during the day. The same electricity prices are used for the province of Ontario. In either case of four or six devices, using the delay reduced the total cost since the requests were delayed for the off-peak periods whenever possible. For example, in the case of four devices without delay and priority, the total cost for 210 days was $\$ 128.1$; however, the cost when giving priority was reduced to $\$ 125.6$, resulting in savings of approximately $\$ 3$ for this period, while the cost when a delay was used was reduced to $\$ 79.4$, resulting in savings of approximately $\$ 49$ for this period.

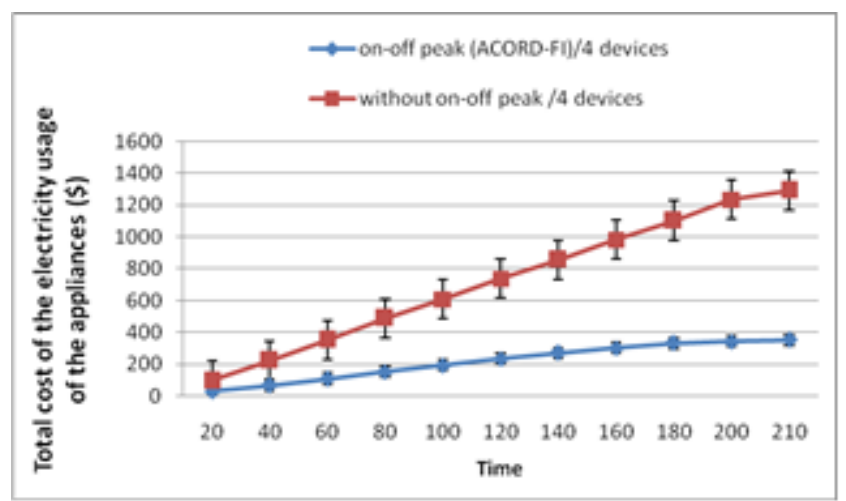

Fig. 11. The total cost of the electricity consumed by four basic devices for the cases of on-off peak and without on-off peak in Jordan

Fig. 11 shows the relation between the time and total cost of energy consumption in dollars for the cases when on-off peak is used (similar to ACORD-Fi) and the case when on-off peak is not used. In this set of experiments, we used the four basic devices discussed in Section I. The electricity prices that were applied in Jordan 2015 for the first case of on-off peak were the same prices in Table 3 for the province of Jordan. The electricity price used for the second case without on-off peak were the average price of the prices in the first case. The simulation period ran from 20 to 210 days. We can see from the figure that using the average price rather than different prices for the on- and off-peak periods costs more.

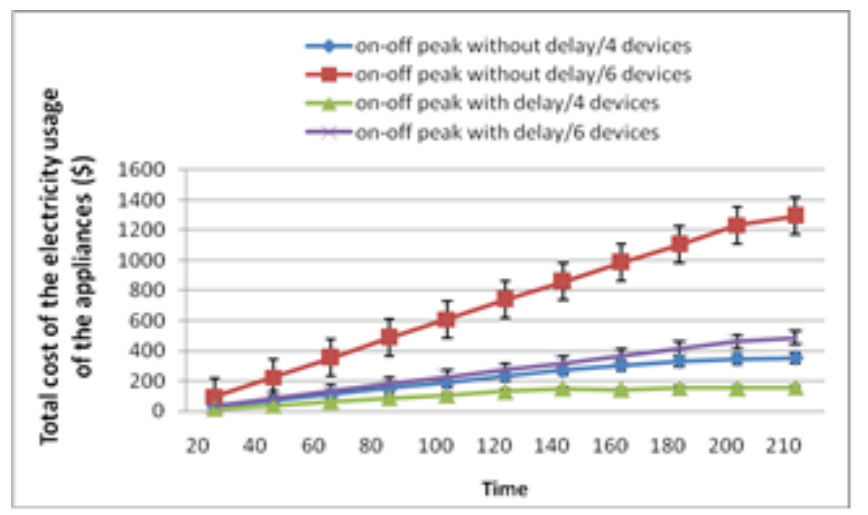

Fig. 12. The total cost of the electricity consumed by four and six devices with and without delay in Jordan 
Fig. 12 shows the relation between the time and total cost of energy consumption in dollars for different cases when onoff peak is used. In this set of experiments, we used the four and six devices as discussed in Section I. The two cases considered for each set of devices are with and without delay for the requests that came during the day. The prices are the same as in Table 3 for the province of Jordan. In either case of four or six devices, using the delay reduced the total cost since the requests were delayed until the off-peak periods whenever possible. For example, in the case of four devices without delay, the total cost for 210 days was $\$ 353.3$; however, the cost when delay was used was reduced to $\$ 156.6$, resulting in a savings of approximately $\$ 197$ for this period.

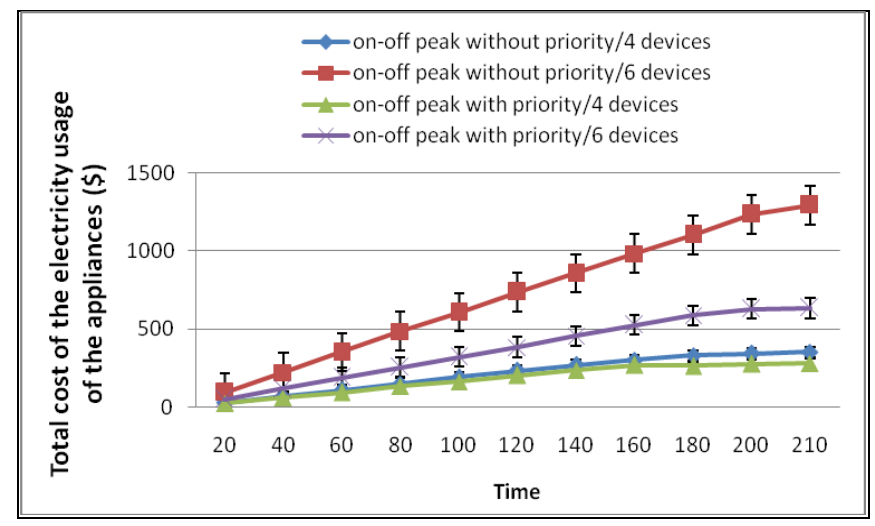

Fig. 13. The total cost of the electricity consumed by four and six devices with and without priority in Jordan

Fig. 13 shows the relation between the time and total cost of energy consumption in dollars for different cases when onoff peak is used. In this set of experiments, we used the four and six devices as discussed in Section I. The two cases considered for each set of devices are with and without priority for the requests that came during the day. The same electricity prices are used for the province of Jordan. In either case of four or six devices, using the priority reduced the total cost since the requests were given priority to some appliances whenever possible. For example, in the case of four devices without priority, the total cost for 210 days was $\$ 353.3$; however, the cost when giving priority was reduced to $\$ 281.8$, resulting in savings of approximately $\$ 72$ for this period.

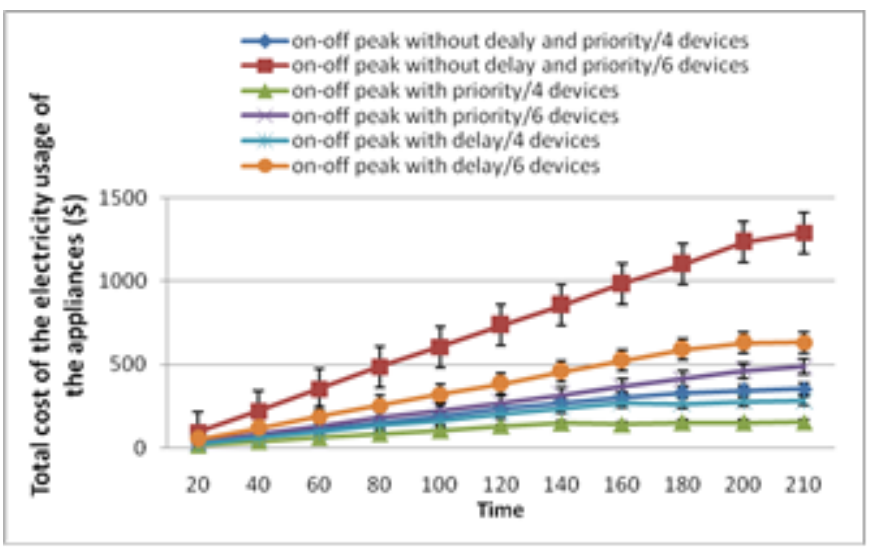

Fig. 14. The total cost of the electricity consumed by four and six devices with and without delay and priority in Jordan
Fig. 14 shows the relation between the time and total cost of energy consumption in dollars for different cases when onoff peak is used. In this set of experiments, we used the four and six devices as discussed in Section I. The three cases considered for each set of devices are with and without delay and priority for the requests that came during the day. The same electricity prices are used for the province of Jordan. In either case of four or six devices, using the delay reduced the total cost, since the requests were delayed until the off-peak periods whenever possible. For example, in the case of four devices without delay and priority, the total cost for 210 days was $\$ 353.3$; however, the cost when giving priority was reduced to $\$ 281.8$, resulting in a savings of approximately $\$ 72$ for this period, while the cost when delay was used was reduced to $\$ 156.6$, resulting in a savings of approximately $\$ 197$ for this period.

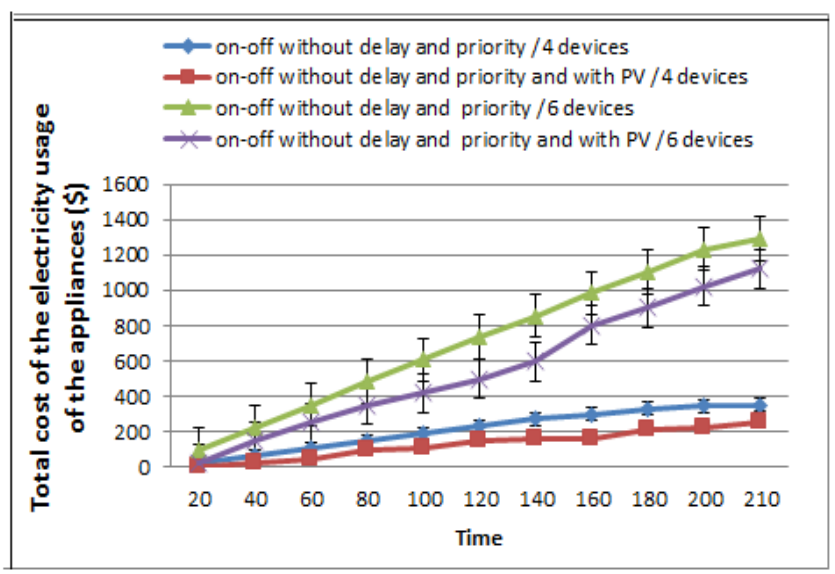

Fig. 15. The Total cost of the electricity consumed by four and six devices using and not using PV and without delay and priority in Jordan

Fig. 15 shows the total cost of energy consumption in dollars during the period of study in the case of with and without using PV and without using any type of proposed scheduling algorithms. The results show that there is a factor of saving when using PV, but still the cost is high because, in our experiments, we used one panel of PV, but in real life, more than one panel can be used, which will give more savings.

Fig. 16 shows the total cost of energy consumption in dollars during the period of study in the case of using and without using PV and with using one of proposed scheduling algorithms: delay. The results show that there is a factor of saving when using $\mathrm{PV}$, and this saving comes from the idea of using the PV energy and then using the delay algorithm, which makes the cost savings in two layers.

Fig. 17 shows the total cost of energy consumption in dollars during the period of study in the case of using and without using PV and with using one of the proposed scheduling algorithms: priority. The results show that there are good savings when using PV, and it can be noticed that using 6 devices with PV is close to using 4 devices, both with priority. As a result, using PV as layer 1 in using appliances and moving to the priority scheduling algorithm gave interested results. 


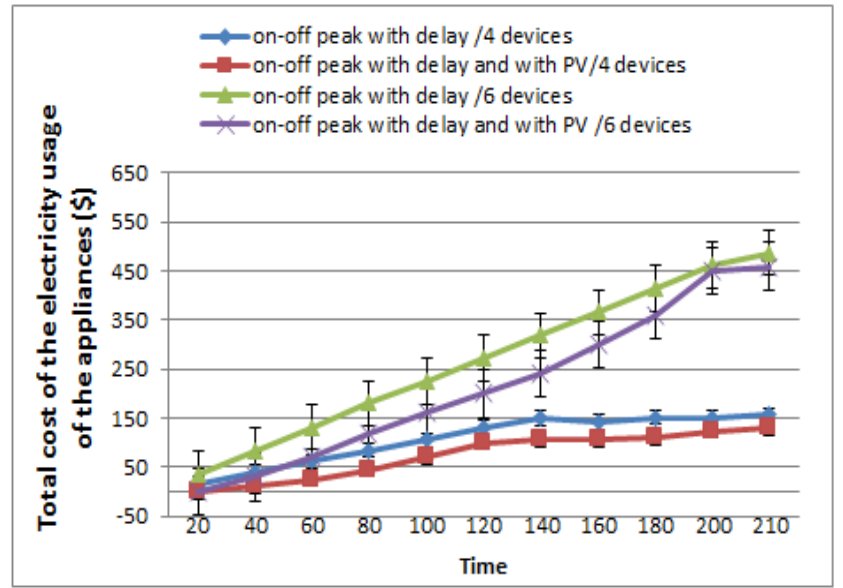

Fig. 16. The total cost of the electricity consumed by four and six devices using and not using PV and with delay in Jordan

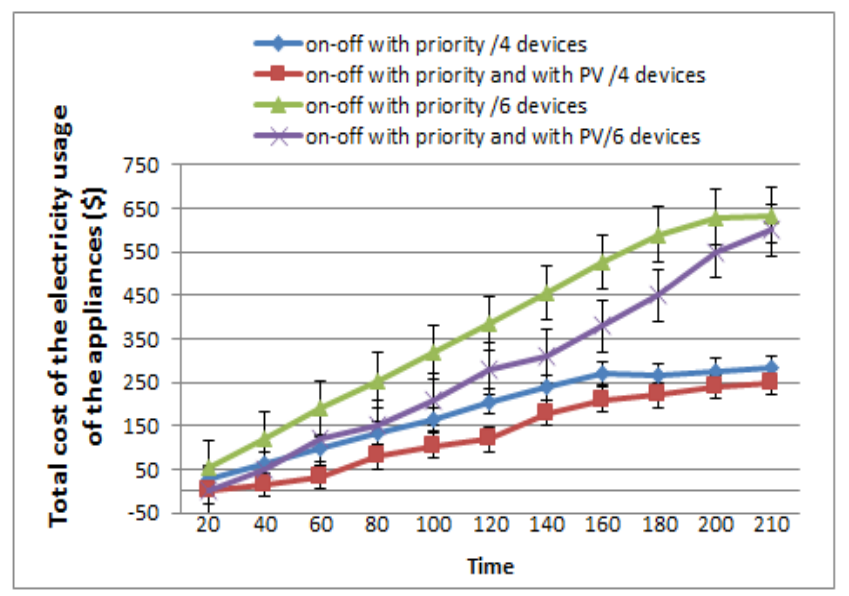

Fig. 17. The total cost of the electricity consumed by four and six devices using and not using PV and with priority in Jordan

\section{CONCLUSIONS AND FUTURE WORKS}

\section{A. Conclusions}

In this work, many experiments were conducted to study the behavior of the proposed schemes, including the preemptive scheduling scheme by giving waiting time and the preemptive scheduling scheme by giving priority. Another purpose of these experiments was to study the efficiency of the proposed schemes when we compare them against the ACORD-FI scheme when using on- and off-peak hours and without using on- and off-peak hours.

Our proposed preemptive scheduling schemes (ACORDWT and ACORD-P) are an enhancement of the nonpreemptive scheduling scheme (ACORD-FI), and they aim to reduce the total energy consumption of home appliances and reduce the total cost of energy bills.

When comparing the ACORD-FI scheme with the two proposed schemes (by giving waiting time and by giving priority) using different number of devices, the results show that the ACORD-FI scheme has the worst savings in cost for the solutions, and the ACORD-WT scheme has the highest savings of cost for the solutions, regardless of the number of devices and peak hour periods.

\section{B. Future Work}

Our proposed work improved the energy cost regarding the ACORD-FI scheme by adding new scheduling algorithms. In our future work, we will try to investigate a new scheduling algorithm to be compared with our work and add new energy sources and new devices.

\section{REFERENCES}

[1] T. Anderson, T. Bon, L. Backer"Basic Electrical Terms and Definitions" North Dakota State University of Agriculture and Applied Science , 1994, pp. 1-4.

[2] M. Shabanzadeh, M. P. Moghaddam, "What is the smart grid? Definitions, perspectives, and ultimate goals," 28th Power System Conference, Tehran, Iran, pp. 1-5, 2013.

[3] W. Wang, Z. Lu "Cyber security in the smart grid: Survey and challenges," vol. 57, pp. 1344-71, April 2013.

[4] R. Stamminger, "Synergy potential of smart appliances," De-liverable 2.3 of Work package 2 from the Smart-A project, University of Bonn, March 2009.

[5] I. Ipakchi and F. Albuyeh, "Grid of the future," IEEE Power Energy Magazine, vol. 7,pp. 52-62, March-April 2009.

[6] V. Gungor, S. Bin Lu, G. Hancke, "Opportunities and challenges of wireless sensor networks in smart grid," IEEE Transactions on Industrial Electronics, vol. 57, pp. 3557-3564, October 2010

[7] T. Li, D. Baumberger, S. Hahn, "Efficient and scalable multiprocessor fair scheduling using distributed weighted round-robin," Proceedings of the 14th ACM Sigplan Symposium on Principles and Practice of Parallel Programming, vol. 44, pp.65-74, April 2009.

[8] I. Khan, A. Mahmood, N. Javaid, S. Razzaq, R. Khan, M. Ilahi, "Home energy management systems in future smart grids," Nadeem Javaid, COMSATS Institute of IT, Islamabad, www.javaid.com, pp. 459-464, 2013.

[9] M. Burcea, W. K. Hon, H. H. Liu, P. W. H. Wong, D. K. Y. Yau, "Scheduling for electricity cost in smart grid," Springer International Publishing, vol. 8287, pp. 306-317, 2013.

[10] C. S. Choi, J. Han, W. K. Park, Y. K. Jeong, I. W. Lee, "Proactive energy management system architecture interworking with smart grid," IEEE 15th International Symposium on Consumer Electronics(ISCE) pp. 621-624, June 2011.

[11] M. Erol-Kantarci, H. T. Mouftah. "TOU-Aware Energy Management and Wireless Sensor Networks for Reducing Peak Load in Smart Grids," IEEE Vehicular Technology Conference, pp. 1-5, May 2010.

[12] M. Erol-Kantarci, H. T. Mouftah, "Using wireless sensor networks for energy-aware homes in smart grids," IEEE Symposium on Computers and Communications, 2010, pp. 456-458.

[13] M. Erol-Kantarci, H. T. Mouftah, "Wireless sensor networks for costefficient residential energy management in the smart grid," IEEE Transactions on Smart Grid, vol. 2, pp. 314-325, June 2011.

[14] M. Erol-Kantarci, H. T. Mouftah, "Wireless sensor networks for smart grid applications," IEEE. Saudi International Electronics, Communications And Photonics Conference (SIECPC) 2011, pp. 1-6.

[15] "Poisson process model (Negative exponential distributed)," http://www.pamvotis.org/vassis/RandGen.htm.

[16] A. Imamura, S. Yamamoto, T. Tazoe, H. Onda, H. Takeshita, S. Okamoto, et al., "Distributed demand scheduling method to reduce energy cost in smart grid," IEEE Humanitarian Technology Conference (R10-HTC) 2013, pp. 148-153, Aug 2013.

[17] P. LI, S GUO, Z. CHENG, "Joint optimization of electricity and communication cost for meter data collection in smart grid," IEEE Transactions on Emerging Topics in Computing, vol. 1, pp. 297-306, December 2013.

[18] A. H. Mohsenian-Rad, A. Leon-Garcia, "Optimal residential load control with price prediction in real-time electricity pricing environments," IEEE Transactions on Smart Grid, vol. 1, pp. 120-133, September 2010. 
[19] E. Pouresmaeil, J. M. Gonzalez, C. A. Canizares, K. Bhattacharya, "Development of a smart residential load simulator for energy management in smart grids," IEEE Transactions on Power System, vol 4, pp. 1-8, Feb 2013.

[20] M. Erol-Kantarci, H. T. Mouftah. "Demand Management and Wireless Sensor Networks in the Smart Grid," Energy Management system book, Aug 2012.

[21] "Hydro Ottawa TOU rates," https://hydroottawa.com/accounts-andbilling/residential/time-of-use/rate-periods .

[22] X. Chen, T. Wei, S. Hu., "Uncertainty-aware household appliance scheduling considering dynamic electricity pricing in smart home,"
IEEE Transactions on Smart Grid, vol. 4, no. 2 pp. 932-941, March 2013.

[23] S. Bera, P. Gupta, S. Misra, "D2S: Dynamic demand scheduling in smart grid using optimal portfolio selection strategy," IEEE Transactions on Smart Grid, vol.6, no. 3, pp.1434-1442, March 2015.

[24] K. Ma, T. Yao, J. Yang, X. Guan, "Residential power scheduling for demand response in smart grid," International Journal Of Electrical Power \& Energy Systems vol. 78, pp: 320-325, 2015.

[25] M. Erol-Kantarci, H. T. Mouftah, "Wireless sensor networks for domestic energy management in smart grids," IEEE Biennial Symposium on Communications (QBSC) 2010, pp. 63-66, May 2010 